Research Paper:

\title{
Predictive Effects of Neuroticism and Emotional Intelligence on Bullying Behavior Among Male College Students
}

\author{
Stephen Oluwaseun Emmanuel ${ }^{1 *}$ (D), Mohammed Tahan ${ }^{2}$ (iD) \\ 1. Department of Educational Foundations and Counselling, Adeyemi College of Education, Ondo. \\ 2. Young Researchers and Elite Club, Birjand Branch, Islamic Azad University, Birjand, Iran.
}

$\begin{gathered}\text { Use your device to scan } \\ \text { and read the article online }\end{gathered}$
Among Male College Students. Avicenna J of Neuropsychophysiology. 2018; 5(2):81-88. http://dx.doi.org/10.32598/ajnpp.5.2.81
dof http://dx.doi.org/10.32598/ajnpp.5.2.81

(c) (i) (5)

Article info:

Received: 05 Sep 2017

Accepted: 10 Jan 2018

Available Online: 01 May 2018

Keywords:

Neuroticism, Emotional intelligence, Bullying, Students, College

\begin{abstract}
Introduction: School bullying is one of the most prevalent issues facing school personnel today and the threat of this behaviour to a safe school environment.

Objectives: The study was designed to examine the predictive effects of neuroticism and emotional intelligence on the bullying behavior of students.

Materials and Methods: A descriptive survey design was adopted for the study. The study participants consisted of 130 randomly-selected students from a college that is predominantly for boys in Ondo State, Nigeria. Three standardized scales were used to obtain data from the participants. Then, Pearson product-moment correlation, and multiple regression analysis were used to analyse the data collected, by SPSS V. 25 and AMOS V. 24.

Results: Three research hypotheses were tested at 0.05 level of significance. The result revealed a significant relationship between neuroticism, emotional intelligence and bullying behavior among college students. Neuroticism and emotional intelligence accounted for $25 \%$ of the variation of bullying behavior and contributed significantly to the prediction.

Conclusion: Based on these findings, school counsellors and psychologists are recommended to assist in training students who score high on neuroticism and help them understand and manage their personality type effectively without posing threats to others.
\end{abstract}

\section{Introduction}

ately, research concerning bullying behavior has moved from merely assessing the prevalence of bullying behavior; to identifying the psychological antecedents to bullying behaviors, taking the study further from the workplace to schools by the investigating into the precursors of bullying behavior. Bullying which is a deviant behavior is the act of intimidating, frightening, threatening or abusing a weaker person by making the person vulnerable. Bullying is repeated negative behavior that

* Corresponding Author:

Stephen Oluwaseun Emmanuel, MSc.

Address: Department of Educational Foundations and Counselling, Adeyemi College of Education, Ondo.

Tel: +23 (481) 40707939

E-mail:emmanuelstephen977@gmail.com 
is carried out against people who cannot defend themselves. Over the years, reaching a consensus on the definition of bullying has been a significant challenge among researchers. However, Effrosyni and Theodoros in an exceedingly meta-analytic study discovered that the various definitions that existed share one similarity: That's, 'bullying is perceived as a set of aggression' [1]. Bullying behavior can be exhibited physically by kicking/jerking; punching, hitting, beating, etc. this form of bullying has been reported to be predominant among the males [2].

Verbal or psychological bullying, which is commonly reported among females could be exhibited by: exclusion or segregation, gossip, rumour spreading/chit-chat, name calling, chatter, ranting etc. although, there is a sparse record on the prevalence of bullying in the $\mathrm{Ni}$ gerian education system, this can be attributed to the culture of insufficient statistical records. However, it can be observed that the prevalence of bullying in Nigerian schools is enormous and requires an urgent attention in curbing it. The literature on bullying behavior shows that researches on bullying in schools date back to at least the 1980s [3]. There has been a growing body of analysis on the way to tackle the matter of bullying at college [4-6].

Bullying behavior that poses a heavy challenge to high school directors remains current in faculties, whereas Olweus in 1978 reportable that boys have interaction in additional direct physical bullying than females; ladies have interaction in additional indirect bullying, like spreading rumors and manipulation of friendly relationship. Avows that physical bullying prevails among males and psychological bullying among females [2]. what is more, Felix and McMahon found that males use physical victimization, harming others through violence, whereas females use relative victimization, harming others by damaging their relationships [7].

A review of literature gives the idea that researchers agree that males mostly are reported to bully physically while the females' folks predominantly bully verbally and psychologically. Found that, in general, males bully quite females, males square measure preponderantly browbeaten by males, which females square measure equally browbeaten by males and females [2]. Later on, cited in Effrosyni, and Theodoros replicated these results. nonetheless, they steered that the prevalence of feminine bullies declined steady with age, however the prevalence of male bullies remained roughly constant from the ages of eight to sixteen [1]. This suggestion justifies the prevalence of bullying among male college students. Bullying among students has led to socio-personal and academic problems such as; truancy, gangsterism, dismissal from school, academic failure to both the victim and the bully. It follows that this problem, if not prevented, could affect educational, human and consequently, the society as a whole [2]. This article aims at adding to the existing knowledge on bullying behavior and most importantly, investigate how far and to what extent neuroticism and emotional intelligence influence bullying behavior among students.

Neuroticism is that the tendency of experiencing negative emotional states, like anxiety, depression, fear, sadness, hostility, anger, guilt, disgust, and vulnerability $[8,9]$. people that exhibit high levels of mental disorder ar at risk of irrational thoughts, impulsive behavior, and applying poor brick ways in nerve-wracking things [10]. people World Health Organization score low in mental disorder tend to be calm and equable, stable, self-content, comfy, unemotional, and hardy [11, 12]. while, the high mental disorder scorer has been represented as anxious, moody, typically depressed, anger, hostility, self-consciousness, thoughtlessness, and vulnerability having robust emotional reactions and have a tendency to be vulnerable $[13,14]$. existent studies have shown that there's a association between mental disorder and bullying behaviour [15-18]. Olweus and Tattum describes victims of bullying as anxious, insecure, lonely, abandoned, physically weaker than their peers, ar afraid to be hurt, they need poor social skills and realize it tough to form friends, they're sensitive, quiet, withdrawn, cautious and keep, they cry or become angry quickly, they're insecure and suffer from low vanity, and that they ar unable to defend themselves [19, 20]. a number of these traits ar wont to characterize people that score high in mental disorder [21].

Keeping track of existent literature on the connection between neurosis and bullying behavior; it had been determined that consistent nexus exist between neurosis and bullying behavior. in an exceedingly comprehensive take a look at of neurosis on some varieties of bullying like indirect bullying and verbal bullying; Mmapula determined a big correlation for neurosis and indirect bullying (victimization) suggesting that learners United Nations agency scored higher on neurosis additionally scored higher on verbal bullying [21]. A correlation was determined within the study for verbal bullying and neurosis, however not for different varieties of bullying victimization. The findings from the study show that neurosis and indirect bullying were powerfully correlated; previous studies by validatory this $[15,16,22]$. in an exceedingly similar study, Harris unconcealed that neurosis and conscientiousness were considerably associated with victimization (indirect bullying) [23]. 
Adding different psychological variables to check the influence of neurosis on bullying behavior, tennis player and O'Moore reported that kids United Nations agency intimidated had higher scores on sociableness, neurosis, and psychoticism compared to their counterparts United Nations agency failed to bully [14]. Mitsopoulou and Giovazolias found that higher levels of neurosis and sociableness were related to each bullying committal and bullying using [22]. Idemudia concurred to the current by revealing that learners with high scores in psychoticism and neurosis additionally had high scores on bullying behaviour [24].

Adding different psychological variables to check the influence of neurosis on bullying behavior, tennis player and O'Moore reported that kids United Nations agency intimidated had higher scores on sociableness, neurosis, and psychoticism compared to their counterparts United Nations agency failed to bully [14]. Mitsopoulou and Giovazolias found that higher levels of neurosis and sociableness were related to each bullying committal and bullying using [22]. Idemudia concurred to the current by revealing that learners with high scores in psychoticism and neurosis additionally had high scores on bullying behaviour [24].

Individuals differ in their abilities, competencies, and dispositions to use and process emotional information, thereby differing in their behaviors and the extent to which they successfully adapt. This individual difference variable is known as emotional intelligence. Emotional intelligence is a mastery of acceptable approaches for managing one's feelings, expressing seemingly negative emotions in proper behaviors, and ultimately acting empathetically. Mayer and Salovey define it as the ability to express, perceive, understand and manage emotions [25]. From the above, emotional intelligence is a skill that can be acquired through training. With the growth of the Emotional Intelligence literature, two distinct perspectives of Emotional Intelligence have been proposed: ability-based and trait-based, that each has their approach to measuring Emotional Intelligence [26]. The ability-based defines Emotional Intelligence as a set of emotion-related cognitive skills, meeting traditional standards for intelligence $[27,28]$. On the opposite hand, the trait-based approach defines Emotional Intelligence as a group of emotion-related inclinations, attitudes, and self-perceptions settled at the lower levels of the gradable temperament taxonomy [29, 30]. For this study, the ability-based approach was adopted.

Emotional Intelligence has been connected to a myriad of social and emotional outcomes over the past twenty years of analysis [31]. it's been tested that peo- ple high on Emotional Intelligence square measure a lot of seemingly to report positive relations with others and fewer seemingly to report negative interactions with shut friends [32]. High levels of emotional intelligence were found to be related to low levels of face-to-face victimization in several studies [33]. Extant research has proven that Emotional Intelligence is negatively related to bullying behaviors and victimization. For instance, Sancho et al., in a meta-analysis across 19 studies found that individuals with higher Emotional Intelligence levels exhibited less aggressive behavior than those with lower Emotional Intelligence [34].

This portends that people WHO exhibit bullying square measure probably to own low levels of emotional intelligence. Emotional intelligence is important in developing fellow feeling, friendly, kind-heartedness, and understanding of the way to affect and manage emotions with success. Therefore, cultivating emotional intelligence skills in youngsters too soon is crucial as a result of equipping them with social and emotional skills to affect feelings and things can facilitate mitigate bullying down the road. Over the years, scientific research has been focused mainly on the factors influencing the development of students with the aim of improving their quality of life. This study would, therefore, be of great importance as it would add to the existing body of knowledge in adolescent and educational psychology. It would be significant to students and parents providing knowledge on the understanding of bullying behavior and its consequences. The findings of this study would equally be of great importance to school instructors, administrators, professional counselors in that if they could make use of the findings to redress the problem of bullying behavior among students. This study is designed to look into the bullying behaviors of students. Therefore, the study would seek to determine the effects of neuroticism and emotional intelligence on the bullying behavior of students.

\section{Materials and Methods}

This study adopted a descriptive survey design of expost facto type. The population for this study consists of 130 randomly selected students from a college that is predominantly for boys in Ondo State, Nigeria. The selected classes are the senior classes that are 14-18. The age of the participants ranged from 12 to 15 , with the mean age of 13.06. The following standardized instruments were used for this study: the validity and reliability of the instrument was assessed with the help of 
confirmatory factor analysis (CFA). The following questionnaires were used for data collection:

Emotional Intelligence Scale (EIS) was assessed with emotional intelligence form developed by Schutte et al. it's a cardinal [33]. Item scale structured in a very 5-point Likert format [35]. Example of things within the scale area unit "I understand once to talk regarding my issues to others", "I expect goodies to happen". A high score indicates associate magnified level of emotional intelligence, whereas low scores indicated a attenuated level of emotional intelligence. In this study the confirmatory factor analysis for the scale resulted in a single factor (0.60), this is consistent with the result from the developers of the instrument. The Cronbach's alpha coefficient of for this study is $\mathbf{0 . 8 4}$. Consequently, the instrument was proven to be valid and reliable for the participants.

Neuroticism Scale is the subsection of the Big-Five model developed by Costa and McCrae was adopted for this study [36]. The scale consists of eight (8) items. The scale was developed in a five-point Likert format such that the high scores would imply reduce occurrences and low scores increased occurrences. The scale constructs discovered a satisfactory level of internal consistency, a decent model match was found for the measure model (First-order CFA model) the measurement model result shows that Chi-square value is $\mathbf{1 1 1 4 . 0 2 2}$ and $\mathrm{P}$ value $=0.000$. Testing the reliability of the scale, it was found to have good psychometric properties, with Cronbach's alpha $=0.680$.

The BPBQ (Bullying Participants Behavior Questionnaire) is intended to measure children and adolescents' perceptions of bullying in their school and includes assessment of behaviors associated with five different participant roles: bully, the victim, defender of the victim, assistant to the bully, and outsider [37]. The scale measures the level of bullying behavior as exhibited by the participants. The result of the Confirmatory Factor Analysis (CFA) revealed that all five subscales correlate with each other. This was used to attest to the validity of the scale. Testing the reliability of the scale, it was found to have good psychometric properties with Cronbach's alpha of 0.65 .

The researchers were assisted by a National Youth Service Corp member in the administration and collection of the instruments from the students. Permission was obtained from the significant authorities in the school. The participants were adequately informed of the confidentiality of the information provided and also the have to be compelled to be precise and truthful in filling the form. The participants gave appropriate informed consent. However, Objectives of the study were explained to parents. Verbal informed consent was obtained from parents, and complies with the ethical standards of the Nigerian Health Research Ethics Committee.

The relationship between the independent variables and the dependent variable was ascertained using Pearson product moment correlation while multiple regression was used to determine the predictive capacity of the independent variables. SPSS V. 25 and AMOS V. 24 Laptop programmes were used in the data analysis.

\section{Result}

Table 1 shows there are significant positive relationships among the three variables in the study with Emotional Intelligence and Bullying having the strongest relationship at r-value of -0.112 .

Going by the result presented in table 2, the two independent variables (neuroticism and emotional intelligence), jointly yielded a coefficient of multiple regression $(R)$ of 0.512 , a multiple correlation square $\left(R^{2}\right)$ of 0.262 and an adjusted multiple correlation square $\left(R^{2}\right)$ of 0.250 . This shows that $25 \%$ of the total variance in bullying behavior of the participants is accounted for by the combination of the two independent variables. The table as well indicates that the analysis of variance of the multiple regression data produced an F-ratio value which was significant at 0.05 level $\left(F_{117.748}=22.040, P<0.05\right)$. The findings thus, confirm that neuroticism and emotiona intelligence are potent predictors of bullying behavior.

From the result displayed in Table 3, each of the independent variables made significant contributions to the prediction of bullying behavior in varying weights. The results indicated that the following beta weights represent the predictive strength of the independent variables observed in accordance with the most effective to the least; Neuroticism, $(\beta=0.541, t=6.637, P<0.05)$ and Emotional intelligence, $(\beta=-0.039, t=-2.008, P \geq 0.05)$.

\section{Discussion}

Analysis of the connection between neuroticism, emotional intelligence and bullying conduct demonstrates that there is a favorable and substantial correlation between the factors tested and the measure of criterion (intimidation conduct). This indicates that neuroticism and emotional intelligence may predict bullying conduct among masculine college pupils. 
Table 1. Descriptive statistics and correlation among variables

\begin{tabular}{cccc}
\hline Variables & Mean \pm SD & Neuroticism & Emotional Intelligence \\
\hline Neuroticism & $21.48 \pm 2.90$ & 0.01 & 0.01 \\
$\begin{array}{c}\text { Emotional } \\
\text { intelligence }\end{array}$ & $82.83 \pm 11.31$ & 0.325 & -0.112 \\
\hline Bullying & $31.94 \pm 3.08$ & 0.523 & 0.01 \\
\hline
\end{tabular}

AJNPP

Table 2. Summary of regression analysis between predictor variables and bullying behavior

\begin{tabular}{ccccc}
\hline Source of Variation & DF & Sum of Squares & Means Square & F-ratio \\
\hline Regression & 2 & 235.495 & 117.748 & 22.040 \\
Residual & 662.473 & 124 & 5.343 \\
Total & 897.969 & 126 & 5.343
\end{tabular}

$\mathrm{R}=0.512$

$\mathrm{R}^{2}=0.262$

AJNPP

Adj. $R^{2}=0.250$

Std. Error Estimate=2.31139

Regarding to what magnitude each of the two independent variables adds to the forecast, Table 3 shows that Emotional Intelligence is the best predictor of intimidation conduct among the respondents. Although the r-value $(-0.112)$ for emotional intelligence is weakly significant Neuroticism also predicts well. These findings are in agreement with findings from [16-18]. These studies affirm that neuroticism leads to bullying behavior. The reason for this could be because of the emotional states that are connected to neuroticism. Students who score high in neuroticism tend towards being hostile and having a feeling of disgust to others which by implication may cause them to bully others, acquiesces with this [8]. It is well known in psychology that females tend slightly more towards neuroticism than males do [38]. Nevertheless, from the results of this study, neuroticism is a potent predictor of bullying behavior among male college students, therefore it can be gathered that the bullying behavior reported in this study as perceived by the participants (who are majorly males) can be related to physical bullying which is predominant among males and not other forms of bullying especially, verbal and psychological bullying which is commonly reported among the female folks [2]. Neuroticism is not only a cause of bully behavior it is also a consequence of being bullied [38, 39]. The result from this study, showing neuroticism to be a significant predictor of bullying behavior can be clarified further that, neuroticism do not only predict bullying behavior, but it is also a subsequent effect of bullying behavior on its victims.

The study as some other studies has several limitations that may restrict the generalizability of its findings. First, this study is restricted to a few samples of male college students who may not be enough sample to predict the bullying behavior of male college students in a vast population. Secondly, the college students in this context are limited to only secondary school students in a college in Ondo State, Nigeria.

Finally, the findings of this descriptive study are at best correlational, and no conclusive statements on causal effects can be made. Consequent upon this, the following recommendations are made: 1 . School Counsellors

Table 3 Relative contribution of the independent variables to the prediction of bullying behavior

\begin{tabular}{|c|c|c|c|c|c|}
\hline \multirow{2}{*}{ Predictor } & \multicolumn{2}{|c|}{ Unstandardized Coefficients } & \multirow{2}{*}{$\begin{array}{c}\text { Standard Co-Efficient } \\
\text { Beta }\end{array}$} & \multirow{2}{*}{$\mathbf{t}$} & \multirow{2}{*}{ Sig. } \\
\hline & B & Std. Error & & & \\
\hline Neuroticism & 0.549 & 0.083 & 0.541 & 6.637 & 0.0001 \\
\hline Emotional intelligence & -0.039 & 0.019 & -0.164 & -2.008 & 0.047 \\
\hline
\end{tabular}


and Psychologists should assist in training students who score high on neuroticism as to help them in understanding and as a result manage their personality type effectively without posing threats to others; 2. Emotional intelligence instruction should be included in the school pupils' engagement program to allow them to create the life skills needed for ideal working and to reduce bullying behaviour; 3 . With the knowledge that neuroticism has a relationship with bullying behavior, personality tests should be administered to students to test their personality types to identify students who record high scores in neuroticism and as such provide the necessary intervention to them; 4 . A conducive environment that encourages the development of appropriate emotional intelligence should be provided to students in school; 5. Identifying factors related to potential victims of bullying behaviors may offer an opportunity in the educational setting to improve anti-bullying programs.

Positive Clinical Implications of the work: This study lends support for clinicians to take an active and holistic approach in educating clients of the implication of their personality type on their behaviour pattern. This study helps clinicians in identifying the effect of the two predictor variables in the prediction of bullying behaviour among college students. This study helps clinicians to identify potential bullies among the students in colleges and how to stem their bully behaviour. This study further revealed to Clinicians that Bullying Participant Behaviours Questionnaire has proved to be a relevant measure to investigate the enormousness of bullying among male college students. Cautions or Limitation of the study: This study is restricted to a few samples of male college students who may not be enough sample to predict the bullying behaviour of male college students in a vast population. The college students in this context are limited to only secondary school students in a college in Ondo State, Nigeria. The findings of this descriptive study are at best correlational, and no conclusive statements on causal effects can be made.

\section{Conclusion}

The study has attempted to identify possible causes of bullying behaviors. Also, neuroticism has shown to be vital in the determination of bullying behavior among the participants. The findings become important in redressing the problem of bullying behavior and its patterns of occurrence. The findings of this study carry its peculiarities that are essential for further studies. The researchers desire that future studies should extend to tertiary education students and should include variables such as; religion, age, and socio-economic status.
It is also suggested that a more robust study using more personality variables and the inclusion of both genders to ascertain the level of bullying by gender.

\section{Ethical Considerations}

\section{Compliance with ethical guidelines}

All ethical principles were considered in this article. The participants were informed about the purpose of the research and its implementation stages; they were also assured about the confidentiality of their information; Moreover, They were allowed to leave the study whenever they wish, and if desired, the results of the research would be available to them, and complies with the ethical standards of the Nigerian Health Research Ethics Committee.

\section{Funding}

This research did not receive any specific grant from funding agencies in the public, commercial, or not-forprofit sectors.

\section{Authors' contributions}

All authors contributed in preparing this article.

\section{Conflict of interest}

The author declares that the research was conducted in the absence of any commercial or financial relationships that could be construed as a potential conflict of interest.

\section{Reference}

[1] Effrosyni M, Theodoros G. Personality traits, empathy and bullying behavior: A meta-analytic approach. Aggression and Violent Behavior. 2015; 21:61-72. [DOI:10.1016/j.avb.2015.01.007]

[2] Farrington DP. Understanding and preventing bullying. In : Tonry $\mathrm{M}$, Morris N. editots. Crime and justice. Chicago: University of Chicago Press; 1993. [DOI:10.1086/449217]

[3] Olweus D. Aggression in the schools: Bullies and whipping boys. New York: Wiley; 1978.

[4] Olweus D. Bullying at school: Tackling the problem. Observer 2001; 225:24-6

[5] Warden D. Mackinnon S. Pro-social children, bullies, and victims: An investigation of their sociometric status, empathy and problem-solving strategies. British Journal of Developmental Psychology. 2003; 21:367-85. [DOI:10.1348/026151003322277757] 
[6] Swearer SM, Espelage DL, Vaillancourt T, Hymel S. What can be done about school bullying? Educational Researcher. 2010; 39(1):38-47. [DOI:10.3102/0013189X09357622]

[7] Felix ED, McMahon SD. The role of gender in peer victimization among youth: A study of incidence, interrelations, and social cognitive correlates. Journal of School Violence. 2007; 6:27-44. [DOI:10.1300/J202v06n03_03]

[8] Major DA, Turner JE, Fletcher TD. Linking proactive personality and the Big Five to motivation to learn and development activity. Journal of Applied Psychology. 2006; 91(4):927-35. [DOI:10.1037/0021-9010.91.4.927] [PMID]

[9] Rothmann S, Coetzer EP. The Big Five personality dimensions and job performance. SA Journal of Industrial Psychology. 2003; 29(1):68-74. [DOI:10.4102/sajip.v29i1.88]

[10] Liang C, Lin WS. The interplay of creativity, imagination, personality traits and academic performance. Imagination, Cognition and Personality. 2015; 34(3):270-90. [DOI:10.1177/0276236614568638]

[11] Ewen RB. An introduction to theories of personality ( $7^{\text {th }}$ ed). New York: Psychology Press; 2014. [DOI:10.4324/9781315793177]

[12] Kail RV, Cavanaugh JC. Human development: A life-span view ( $6^{\text {th }}$ ed). Belmont, CA: Wadsworth; 2013.

[13] Costa PT, McCrae RR. Personality disorders and the five-factor model of personality. Journal of Personality Disorders. 1992; 4:362-71. [DOI:10.1521/pedi.1990.4.4.362]

[14] Connolly I, O'Moore M. Personality and family relations of children who bully. Personality and Individual Differences. 2003; 35:559-67. [DOI:10.1016/S0191-8869(02)00218-0]

[15] Teng Z, Liu Y. The role of neuroticism in the relation between self-esteem and aggressive emotion among 1085 Chinese adolescents. Psychology. 2013; 4(10):729-35. [DOI:10.4236/ psych.2013.410103]

[16] Barlett CP, Anderson CA. Direct and indirect relations between the Big 5 personality traits and aggressive and violent behavior. Personality and Individual Differences. 2012; 52:870-5. [DOI:10.1016/j.paid.2012.01.029]

[17] Menesini E, Camodeca M, Nocentini A. Bullying among siblings: The role of personality and relational variables. The British Journal of Developmental Psychology. 2010; 28(4):921-39. [DOI:10.1348/026151009X479402] [PMID]

[18] Tani F, Greenman PS, Schneider BH, Fregoso M. Bullying and the Big Five: A study of childhood personality and participant roles in bullying incidents. School Psychology International. 2003; 24:13146. [DOI:10.1177/0143034303024002001]

[19] Olweus D. Bullying at school: What we know and what we can do. Malden, MA: Blackwell Publishing; 1993.

[20] Tattum D. Understanding and managing bullying. Oxford: Heinemann School Management; 1993.

[21] Mmapula PM. [Relationship between personality factors and bullying Behavior of learners in Ngaka Modiri Molema District (English)]. [MA Thesis]. Mafikeng Campus: North-West University, 2016.

[22] Mitsopoulou E, Giovazolias T. Personality traits, empathy and bullying behavior: A meta-analytic approach. Aggression and Violent Behavior. 2015; 21:61-72. [DOI:10.1016/j.avb.2015.01.007]
[23] Harris MA. Personality and self-compassion of former victims of bullying (Honour's thesis, University of Arizona, Arizona) [Internet]. 2011 [Cited Oct 2011]. Available from: http://arizona.openrepository.com/arizona/handle/10150/144360

[24] Idemudia ES. EPQ and self-esteem scores of male and female bullies in Mafikeng schools, South Africa. Gender and Behavior. 2013; 11(1):5208-19.

[25] Mayer JD, Salovey P. What is emotional intelligence? In: Salovey P, Sluyter D. editors. Emotional development and emotional intelligence: Implications for educators. New York: Basic Books; 1997.

[26] Parker JDA, Keefer KV, Wood LM. Toward a brief multidimensional assessment of emotional intelligence: Psychometric properties of the Emotional Quotient Inventory-Short Form. Psychological Assessment. 2011; 23(3):762-77. [DOI:10.1037/a0023289] [PMID]

[27] Mayer John D, Caruso David R, Salovey P. Emotional Intelligence Meets Traditional Standards for Intelligence. Intelligence. 1999; 27:267-98. [DOI:10.1016/S0160-2896(99)00016-1]

[28] Mayer JD, Salovey P, Caruso DR. Emotional intelligence: New ability or eclectic traits? American Psychologist. 2008; 63(6):503 17. [DOI:10.1037/0003-066X.63.6.503] [PMID]

[29] Petrides KV, Furnham A. Trait emotional intelligence: Psychometric investigation with reference to established trait taxonomies. European Journal of Personality. 2001; 15(6):425-48. [DOI:10.1002/per.416]

[30] Petrides KV, Furnham A, Mavroveli S. Trait emotional intelligence: Moving forward in the field of El. Emotional intelligence: Knowns and Unknowns. 2007; 151-66 (Open Access). [DOI:10.1093/acprof:oso/9780195181890.003.0006]

[31] Stough C, Saklofske DH, Parker JDA. A brief analysis of 20 years of emotional intelligence. An introduction to current advances in El assessment and application. London: Springer; 2009. [DOI:10.1007/978-0-387-88370-0_1]

[32] Lopes PN, Salovey P, Straus R. Emotional intelligence, personality, and the perceived quality of social relationships. Personality and Individual Differences. 2003; 35(3):641-58. [DOI:10.1016/ S0191-8869(02)00242-8]

[33] Kokkinos CM, Kipritsi E. The relationship between bullying, victimization, trait emotional intelligence, self-efficacy and empathy among preadolescents. Social Psychology of Education. 2012; 15:41-58. [DOI:10.1007/s11218-011-9168-9]

[34] Sancho E, Salguero JM, Fernández-Berrocal P. Relationship between emotional intelligence and aggression: A systematic review. Aggression and Violent Behavior. 2014; 19(5):584-91. [DOI:10.1016/j.avb.2014.07.007]

[35] Schutte NS, Malouff JM, Hall LE, Haggerty D, Cooper JT, Golden $C$, et al. Development and validation of a measure of emotional intelligence. Personality and Individual Differences. 1998; 25:16777. [DOI:10.1016/S0191-8869(98)00001-4]

[36] McCrae RR, Costa PT. Validation of the five-factor model of personality across instruments and observers. Journal of Personality and Social Psychology. 1987; 52(1):81-90. [DOI:10.1037/0022 3514.52.1.81

[37] Summers K, Demaray MK. Bullying Participant Behaviors Questionnaire. DeKalb, IL: Northern Illinois University; 2008. 
[38] Anton D. [Big Five Personality Traits and Bullying (English)]. [MA Thesis]. Netherlands: Tilburg University; 2014.

[39] Tahan M, Tajali P, Kalantari M. The theory of mind among deaf children: A review of the Theoretical Foundations. Mediterranean Journal of Clinical Psychology. 2019; 7(1). [DOI: http://dx.doi. org/10.6092/2282-1619/2019.7.1878] 